\title{
Clinical profile on incidence and course of Retinopathy of Prematurity in a tertiary care hospital of Northern India
}

\author{
Parveen Grang', Prempal Kaur ${ }^{2}$, Karamjit Singh ${ }^{3}$, Ashwani Sareen ${ }^{4}$, Bhavkaran Singh ${ }^{5}$ \\ ${ }^{1}$ Senior Resident, ${ }^{2,3}$ Professor, ${ }^{5}$ Medical Officer, Department of Ophthalmology, Regional Institute of Ophthalmology, \\ GMC, Amritsar, Punjab, India, ${ }^{4}$ Professor, Department of Pediatrics, GMC, Amritsar, Punjab, India
}

Background: Retinopathy of prematurity (ROP) is a vaso-proliferative disorder of retina of preterm infants. It remains the leading cause of childhood blindness worldwide. Aggressive posterior retinopathy of prematurity (APROP) is rapidly progressive severe form of ROP. Aims and Objectives: The present study was done to assess incidence and evaluate course of ROP in preterm babies born before 34 weeks and birth weight $<1750$ grams. Materials and Methods: The current study was a two year prospective observational study. Screening of all neonates born with gestational age $\leq 34$ weeks and birth weight $<1750$ grams was done for ROP at 4 weeks of their postnatal age by indirect ophthalmoscopy and followed up till vascularization was complete. All neonates identified with APROP and ROP with plus disease was treated with double-frequency Nd YAG laser. Results: Of 318 neonates screened, $34.9 \%$ neonates (111) were observed to have ROP. $2.5 \%(8 / 318)$ neonates diagnosed with APROP and $4.4 \%$ neonates (14/318) having ROP with plus disease including pre-threshold and threshold ROP were treated with double frequency Nd Yag laser. All 14 treatment requiring ROP babies and 6 APROP babies showed total regression while one neonate with APROP succumbed to septicaemia during follow up and one APROP baby had to be referred to higher centre after he developed partial retinal detachment (RD) (Stage 4a). Conclusion: $34.9 \%$ had ROP, only $6.28 \%$ needed intervention. Laser monotherapy even when administered early has lesser favorable structural and functional outcome in APROP as compared to classical ROP.

Key words: Aggressive posterior retinopathy of prematurity; Nd YAG laser; Retinopathy of prematurity; Treatment outcome
Access this article online

Website:

http://nepjol.info/index.php/AJMS DOI: 10.3126/ajms.v12i7.35097

E-ISSN: 2091-0576

P-ISSN: 2467-9100

Copyright (c) 2021 Asian Journal of Medical Sciences

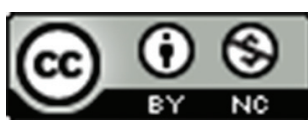

This work is licensed under a Creative Commons Attribution-NonCommercial 4.0 International License.

\section{INTRODUCTION}

Retinopathy of prematurity (ROP) is a vision-threatening vaso-proliferative disorder affecting the retina 4-5 weeks after birth of premature infants who have avascular or incompletely vascularized retina at birth. ${ }^{1}$ The incidence of ROP is increasing with increased survival of preterm infants due to advent of recent developments in resuscitation and improved neonatal care especially in middle income countries like India. ${ }^{2}$

Unrestricted oxygen use led to the first epidemic of ROP in 1940-1950s while the second epidemic in 1970-1980s was thought to be due to increased survival of preterm babies in high-income countries. India and other middleincome countries are facing the "Third epidemic of ROP" related to various factors, such as increased survival of preterm babies, inadequate quality of neonatal care and low coverage of screening and treatment services for ROP. $^{3,4}$

With improvement in neonatal resuscitation methods and increased survival of the preterm babies over a last two decades the incidence of sight threatening ROP requiring urgent laser treatments has also increased. As a result ROP screening strategies are now integrated with many national 
newborn and child health services to ensure healthy newborn outcome. ${ }^{5}$

Incidence and prevalence of ROP in India has been reported to vary between 38\%-51.9\% and 19.2\%-32.4\% respectively. ${ }^{6,7}$ ROP is a multifactorial disease. The low birth weight and gestational age are the most predictive risk factors for the development of ROP. Other contributing neonatal risk factors include fluctuating or uncontrolled oxygen therapy, respiratory distress syndrome, apnea, sepsis, anemia, multiple blood transfusions. Further varied maternal risk factors like diabetes, pregnancy induced hypertension, antepartum hemorrhage may also show significant correlation with development and progression of ROP. ${ }^{8,9}$

All the neonates born with birth weight less than or equal to 2000 grams and of 34 weeks or less gestational age are screened for development of ROP. Neonates with gestational age of more than 34 weeks are screened only in the presence of associated risk factors. ${ }^{5}$ Further babies with ROP are classified according to the international classification of retinopathy of prematurity (ICROP). ${ }^{10}$ Intervention is indicated in all the babies with threshold ROP or aggressive posterior ROP (APROP). APROP, a severe form of ROP is defined as posterior location (zone I or posterior zone II), increased dilation and tortuosity of the posterior pole vessels in all quadrants out of proportion to the peripheral retinopathy with flat extraretinal fibrovascular proliferation (EFP) and a rapidly progressive course. ${ }^{10}$ The treatment prognosis in APROP babies is reported to be poorer than the typical threshold ROP. ${ }^{11}$

Management of APROP may be complicated due to poor visualization of the fundus due to persistent tunica vasculosa lentis or flat growth of neovascularization along the retina. Persistent or recurrent vascular activity and retinal detachment may occur despite appropriate laser ablation, requiring second-stage laser or additional antivascular endothelial growth factor (VEGF) treatment. ${ }^{12}$

Effective screening of all the premature neonates by a trained ophthalmologist in collaboration with paediatrician and timely intervention can successfully result in better visual and structural outcome in ROP. ${ }^{13,14}$

\section{MATERIAL AND METHODS:}

Study design- A two year prospective observational study.

After taking clearance from the institutional ethical committee, a two year prospective observational study was conducted between January 2018 to December 2019 on neonates with gestational age less than or equal to 34 weeks and birth weight $<1750$ grams. Informed consent from the parents was taken in their vernacular language in accordance with the declaration of Helsinki, 1983. Baseline variables of all the enrolled neonates, their neonatal problems, interventions and treatment given during their stay in NICU were recorded.

Data including their age, birth weight, gestational age, maternal and neonate risk factors were recorded. All the enrolled neonates were screened for ROP at 4 weeks after birth after dilating pupil with a mixture of phenylephrine $2.5 \%$ and tropicamide $0.5 \%$ instilled 3 times at 10 minutes interval before the scheduled examination. $2 \%$ proparacaine was instilled and fundus examination was done by the same experienced ophthalmologist using an indirect ophthalmoscope with $20 \mathrm{D}$ lens or $28 \mathrm{D}$ lens.

Further follow up was done 2 weekly for stage 1 , weekly for stage 2, every $2^{\text {nd }}$ or $3^{\text {rd }}$ day for stage 3 and APROP. Babies identified with ROP were grouped into APROP and non APROP groups. All babies with APROP and treatment requiring non APROP neonates were treated with laser ablation of entire avascular retina with near confluent burns by the same experienced ophthalmologist in the presence of neonatologist. Following laser treatment all neonates were followed on 3rd day, 7th day, 2 weeks, 3 weeks and thereafter at 1 month and 3 month.

\section{RESULTS}

Out of 318 neonates screened for ROP between January 2018-December 2019, ROP was observed in 34.9\% neonates (111). APROP was reported in 2.5\% (8 out of 318) babies in our study (Table 1). The mean gestational age of APROP and non APROP babies was (30.5 \pm 1.77 weeks) and ( $31.13 \pm 2.42$ weeks) respectively. The mean birth weight of APROP babies was $1224 \pm 246.42$ grams and in non APROP babies was $1342 \pm 235.03$ grams.

Out of total 318 babies screened for ROP, $34.9 \%$ babies (111) had ROP. $15.4 \%(49)$ were in stage 1, 14.1\% (45) in stage $2,2.5 \%(8)$ in stage 3 and another $2.5 \%$ (8) babies had APROP. Zone 1 ROP was seen in $2.5 \%$ (8) whereas Zone 2 ROP was seen in $32.4 \%$ babies (103). Plus disease was seen in $4.4 \%$ neonates (14) out of which threshold disease was present in 6 babies $(1.88 \%)$ and pre-threshold (type 1) disease was seen in 8 babies (2.5\%).

All 8 APROP babies and 14 neonates with plus disease ROP were treated with double frequency Nd Yag laser. Mean number of laser spots were $2450.50 \pm 1592.12$ (R/E) and $2669.13 \pm 1153.78(\mathrm{~L} / \mathrm{E})$ among APROP neonates and $929.89 \pm 580.43(\mathrm{R} / \mathrm{E})$ and $969.88 \pm 491.83(\mathrm{~L} / \mathrm{E})$ in non- 
APROP infants( threshold ROP).Laser intensity used was in the range of 250-360 and 150-320 in APROP and ROP neonates respectively Table 2 . Re treatment was required in 3 APROP neonates.

Double frequency Nd Yag laser therapy was given in APROP and threshold ROP. Vitreous haemorrhage was observed in one ROP baby (7.14\%) after laser treatment Table 2. It resolved within 4 weeks of observation while another baby with APROP $(14.3 \%)$ had to be referred to higher centre following unfavorable structural outcome in the form of partial retinal detachment (stage 4a). The mean time to regression of ROP was 6.14 2.00 (3-8 weeks).

\section{DISCUSSION}

Of 318 infants screened for ROP between January 2018 and December 2019, 34.9\% babies(111) were observed to have ROP, out of which $15.4 \%$ babies (49) were in stage 1 , $14.1 \%$ (45) in stage 2, 2.5\% (8) in stage 3 ROP and another $2.5 \%$ had APROP (8). Plus disease was present among 8 babies with APROP and 14 babies with ROP (Table 3). Out of 14 babies with ROP threshold disease was present in 6 babies (1.88\%) and pre-threshold (type 1) disease was seen in 8 babies $(2.5 \%)$.

Results were similar to a study conducted on 1738 preterm neonates with gestational age $<34$ weeks and birth weight $<1500$ grams for a period of four years which reported incidence of APROP as $4.37 \% .{ }^{15}$ Yet another 2 year study done on 212 preterm babies by Sardar SK et al., 16.51\% had ROP, out of which $6.6 \%$ (14) had stage 1 and another $6.6 \%$ (14) had stage 2 . None had stage 3 , stage 4 or stage 5 ROP while $3.30 \%$ (7) had APROP. ${ }^{16}$

Study done by Anupama B et al revealed that out of 233 infants, 64(27.4\%) babies had ROP and $6(2.57 \%)$ neonates had Aggressive Posterior ROP (APROP). Out of 64 ROP infants, 24(37.5\%) had stage 2 ROP, $33(51.56 \%)$ stage 3, one baby had stage 4B ROP and $6(9.38 \%)$ neonates had Aggressive Posterior ROP (APROP). ${ }^{17}$ In a retrospective cohort study between March 2005 to August 2015, Freitas et al screened 602 neonate with mean GA of $30.7 \pm 2.5$ weeks and mean BW of $1274 \pm 385 \mathrm{~g}$ and found ROP in 33.9\% (204) neonates. Out of which $160(26.6 \%)$ had developed stage 1 ROP, 26 (4.3\%) stage 2 and $18(3 \%)$ stage 3 ROP. None of the patients had developed stages 4 or 5 ROP while thirty patients $(5.0 \%)$ had developed type 1 prethreshold ROP. ${ }^{18}$

8 babies with APROP and 14 babies with plus ROP disease were treated with double frequency Nd: Yag laser. Mean number of laser spots given in right and left eye of

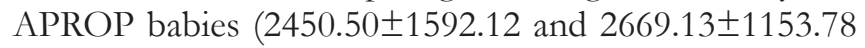
respectively) (Table 1) were more $[929.89 \pm 580.43(\mathrm{R} / \mathrm{E})$ and $969.88 \pm 491.83(\mathrm{~L} / \mathrm{E})]$ than in treatment requiring ROP cases (threshold ROP). Laser intensity used was in the range of 250-360 in APROP and 150-320 in ROP neonates (Table 2). Repeat laser was done in the presence of any skip areas or inadequate response. In our study 5 APROP babies required 1 laser sitting, 2 babies needed 2 sittings and only 1 APROP baby needed 3 sittings whereas among 14 treatment requiring ROP babies, 12 babies regressed after one laser sitting and only 2 babies required 2 laser sittings. All babies were followed up on $3^{\text {rd }}$ day, 7 th day, 2 weeks, 3 weeks and thereafter at 1 month, and 3 month after laser treatment. Of 8 APROP babies, one baby scummed to septicaemia during follow up, 6 babies $(85.75 \%)$ showed complete regression and one baby $(14.3 \%)$ developed unfavorable structural outcome in the form of partial retinal detachment (stage 4a). He was referred to higher centre for further management. Amongst 14 treatment requiring ROP babies' one baby (4.2\%) during laser application developed vitreous haemorrhage which resolved within 4 weeks of observation. Consequently at 3 months follow up complete regression was seen in 100\% of ROP and $85.7 \%$ APROP babies.

Despite early laser photocoagulation, favorable outcome in APROP has been reported between 71\% to $84 \%{ }^{19-21}$ which is lesser than reported in classical ROP $(>90 \%){ }^{22}$ A retrospective study done on babies birth weight $\geq 1500$ grams between January 2006 to December 2009, favorable outcome was observed in $86.2 \%$ eyes (25 out of 29) of 15 infants with APROP after confluent laser photocoagulation. ${ }^{23}$ Similarly other studies also reported more favorable anatomical outcomes by laser monotherapy in infants with non-zone I ROP than in infants with zone I ROP. ${ }^{11,24}$ Vander et al., in his study observed an unfavorable structural outcome in $3(15.7 \%)$ eyes of 19 infants with prethreshold posterior ROP compared to $3(17.6 \%)$ eyes of 17 infants with threshold disease. ${ }^{25}$

Table 1: Demographics of infants requiring treatment

\begin{tabular}{|c|c|c|c|c|c|c|c|}
\hline \multirow{2}{*}{$\begin{array}{l}\text { Stage of ROP } \\
\text { (number of babies) }\end{array}$} & \multicolumn{2}{|c|}{ Laser spots (mean) } & \multicolumn{2}{|c|}{ Laser intensity } & \multicolumn{3}{|c|}{ Laser sitting } \\
\hline & R/E & L/E & R/E & L/E & 1 & 2 & 3 \\
\hline APROP (8) & $2450.50 \pm 1592.12$ & $2669.13 \pm 1153.78$ & $250-360$ & $250-360$ & $5(62.5 \%)$ & $2(25 \%)$ & $1(12.5 \%)$ \\
\hline
\end{tabular}




\begin{tabular}{|c|c|c|c|}
\hline & Non APROP & APROP & \\
\hline \multicolumn{4}{|c|}{ Final outcome } \\
\hline RD & 0 & $1(14.3 .0 \%)$ & $1(4.8 \%)$ \\
\hline VH & $1(7.14 \%)$ & 0 & $1(4.8 \%)$ \\
\hline TR & $14(100 \%)$ & $6(85.7 \%)$ & $20(95.2 \%)$ \\
\hline Total & $14(100 \%)$ & $7(100 \%)$ & $21(100 \%)$ \\
\hline
\end{tabular}

$\mathrm{RD}$ : retinal detachment, $\mathrm{VH}$ : vitreous haemorrhage, TR: total regression

\begin{tabular}{lcc} 
Table 3: Showing distribution of severity of ROP \\
\hline Stages of ROP & 1 & $49(15.4 \%)$ \\
& 2 & $45(14.1 \%)$ \\
& 3 & $8(2.5 \%)$ \\
& 4 & $0(0)$ \\
APROP & 5 & $0(0)$ \\
Zone of ROP & 1 & $8(2.5 \%)$ \\
& 2 & $8(2.5 \%)$ \\
Plus disease & 3 & $103(32.4 \%)$ \\
ROP & & $0(0)$ \\
APROP & \\
Pre-threshold & & $14(4.4 \%)$ \\
Type 2 & $8(2.5 \%)$ \\
Type 1 & \\
Threshold ROP & & $0(0 \%)$ \\
\hline
\end{tabular}

Another study done by Anuja sathar et al on 1738 premature babies, 18 babies who developed APROP were subjected to laser treatment. Mean number of laser spots delivered was $2829.1 \pm 919.1$ burns. Regression was seen in $50 \%$ (9) of babies with one laser sitting whereas another $50 \%$ needed repeat laser. ROP regressed in all except 6 eyes of 4 infants at 3 months follow-up. Additional intravitreal bevacizumab injection was required in these patients. Unfavorable structural outcome in the form of partial retinal detachment (stage IV) occurred in 4 eyes of three patients, for which pars plana vitrectomy was done. ${ }^{15} \mathrm{It}$ concluded that anatomical outcomes without any structural sequelae were achieved in $78.1 \%$ of zone I APROP and $100 \%$ of posterior zone II APROP cases.

$100 \%$ success rate was reported in a study done by Fleming et al. when indirect laser treatment was given much earlier than threshold stage ${ }^{26}$ whereas Shapiro et al reported a 36\% unfavorable outcome rate in zone 1 eyes treated earlier than threshold..$^{27}$

In an observational study between 2008 and 2013 Anupama et al., screened 233 neonates and found that $27.46 \%$ (64) babies had ROP and $2.57 \%$ (6) had APROP. 56.25\% (36) of ROP babies required treatment. All except seven eyes of four APROP babies required single sitting of laser. ROP regression was seen in all (35) except one baby with APROP who progressed to stage $4 \mathrm{~A}$ retinal detachment and required lens sparing vitrectomy. The favorable outcome of laser among the APROP babies (83.3\%) and ROP requiring treatment $(100 \%)$ in the study was comparable to our observations. ${ }^{17}$

\section{Limitations of the study}

We had few limitations in our study. Firstly the sample size was small secondly the patient referred to higher center was lost to follow up and finally we did not have Retcam for more precise interpretations.

\section{CONCLUSION}

Incidence of ROP in the current study was $34.9 \%$ out of which $15.4 \%$ (49) were in stage $1,14.1 \%$ in stage $2,2.5 \%$ in stage 3 and another $2.5 \%(8)$ babies had APROP. Zone 1 ROP was seen in $2.5 \%$ whereas Zone 2 ROP was seen in $32.4 \%$ babies. Laser was applied to infants with plus disease ( $4.4 \%$ neonates $(14)$ out of which threshold disease was present in 6 babies (1.88\%) and pre-threshold (type 1) disease was seen in 8 babies (2.5\%). Laser monotherapy even when administered early has lesser favorable structural and functional outcome in APROP as compared to results of classical staged ROP.

\section{ACKNOWLEDGEMENT}

The authors take the opportunity to thank Dr Ashwani Sareen, Professor Pediatrics for his whole hearted support for this study.

\section{REFERENCES}

1. Shah PK, Prabhu V, Karandikar SS, Ranjan R, Narendran V, Kalpana N, et al. Retinopathy of prematurity: Past, present and future. World J Clin Pediatr. 2016; 5(1):35-46.

https://doi.org/10.5409/wjcp.v5.i1.35

2. Gilbert C, Rahi J, Eckstein M, O'Sullivan J and Foster A. ROP in middle- income countries. Lancet. 1997; 350:12-14. https://doi.org/10.1016/S0140-6736(97)01107-0

3. Kiranmayee PS and Kalluri V. India to gear up to the challenge of "third epidemic" of retinopathy of prematurity in the world. Indian J Ophthalmol. 2019; 67(6):726-731.

https://doi.org/10.4103/ijo.IJO_700_18

4. Gilbert C. Retinopathy of prematurity: a global perspective of the epidemics, population of babies at risk and implications for control. Early Hum Dev. 2008; 84(2):77-82.

https://doi.org/10.1016/j.earlhumdev.2007.11.009

5. Shukla R, Murthy GVS, Gilbert C, Vidyadhar B and Mukpalkar S. Operational guidelines for ROP in India: A summary. Indian J Ophthalmol. 2020; 68(Suppl 1): S108-S114.

https://doi.org/10.4103/ijo.IJO_1827_19

6. Charan R, Dogra MR, Gupta A and Narang A. The incidence of retinopathy of prematurity in a neonatal care unit. Indian $\mathrm{J}$ Ophthalmol.1995; 43:123-126.

7. Hakeem $\mathrm{AH}$ and Mohamed GB, Othman MF. Retinopathy of 
prematurity: A study of prevalence and Risk factors. Middle East Afr J Ophthalmol. 2012; 19(3):28994.

https://doi.org/10.4103/0974-9233.97927

8. Chang JW. Risk factor analysis for the development and progression of retinopathy of prematuri-ty. PLoS One. 2019; 14(7):e0219934.

https://doi.org/10.1371/journal.pone.0219934

9. Shah VA, Yeo CL, Ling YL and Ho LY. Incidence, risk factors of retinopathy of prematurity among very low birth weight infants in Singapore. Ann Acad Med Singap. 2005; 34(2):169-178.

10. International Committee for the Classification of Retinopathy of Prematurity. The International Classification of Retinopathy of Prematurity revisited. Arch Ophthalmol. 2005; 123(7): 991-999. https://doi.org/10.1001/archopht.123.7.991

11. O'Keefe M, Lanigan B and Long VW. Outcome of zone 1 retinopathy of prematurity. Acta Ophthalmol Scand. 2003; 81(6): 614-612. https://doi.org/10.1111/j.1395-3907.2003.00171.x

12. Gunn DJ, Cartwright DW and Gole GA. Prevalence and outcomes of laser treatment of aggressive posterior retinopathy of prematurity. Clin Exp Ophthalmol. 2014; 42(5):459-456. https://doi.org/10.1111/ceo.12280

13. Banach $\mathrm{MJ}$ and Berinstein D. Laser therapy for retinopathy of prematurity. Curr Opin Ophthalmol. 2001; 12 (3): 164-170. https://doi.org/10.1097/00055735-200106000-00003

14. Good WV, Hardy RJ, Dobson V, Palmer EA, Phelps DL, Quintos M, et al. The incidence and course of retinopathy of prematurity: Findings from the early treatment for retinopathy of prematurity study. Pediatrics. 2005; 116(1):15-23. https://doi.org/10.1542/peds.2004-1413

15. Sathar A, Shanavas A, Jasmin LB and Girija Devi PS. Outcome of Aggressive Posterior Retinopathy of Prematurity in a Tertiary Care Hospital in South India. Journal of Medical Science and Clinical Research. 2017; 5(4): 20885-20891.

https://doi.org/10.18535/jmscr/v5i4.182

16. Sardar SK and Pal S. Profile of retinopathy of prematurity in late preterm newborn in a district level special newborn care unit of Eastern India. Int J Contemp Pediatr. 2018;6:163-167. https://doi.org/10.18203/2349-3291.ijcp20185202

17. Anupama B, Jain R, Hegde V, Sudhir S and Shanbhu R. A study of clinical profile and treatment outcome in pre term ba-bies with retinopathy of prematurity. Ind J Clin Exp Ophthalmol. 2018; 4(3):368.

https://doi.org/10.18231/2395-1451.2018.0081
18. Freitas $\mathrm{AM}$, Mörschbächer $\mathrm{R}$, Thorell MR and Rhoden EL. Incidence and risk factors for retinopathy of prematurity: a retrospective cohort study. Int J Retin Vitr. 2018 (4):20.

https://doi.org/10.1186/s40942-018-0125-z

19. Drenser KA, Trese MT and Capone A. Aggressive posterior retinopathy of prematurity. Retina. 2010; 30: S 37-S 33. https://doi.org/10.1097/IAE.0b013e3181cb6151

20. Sanghi G, Dogra MR, Das P, Anand V, Amod G and Saurabh D. Aggressive posterior retinopathy of prematurity in Asian Indian babies: Spectrum of disease and outcome after laser treatment. Retina. 2009; 29:1335-1339. https://doi.org/10.1097//AE.0b013e3181a68f3a

21. Jalali $S$, Kesarwani $S$ and Hussain $A$. Outcomes of a protocol-based management for zone 1retinopathy of prematurity: The IndianTwin Citities ROP screening program report number. Am J Ophthalmol. 2011; 151:719-724.

https://doi.org/10.1016/j.ajo.2010.10.007

22. Early Treatment for Retinopathy of Prematurity Cooperative Group. Revised indications for the treat-ment of retinopathy of prematurity: Results of the early treatment for retinopathy of prematurity randomized trial. Arch Ophthalmol. 2003; 121:1684-1696.

https://doi.org/10.1001/archopht.121.12.1684

23. Sanghi G, Dogra MR, Katoch D and Gupta A. Aggressive posterior retinopathy of prematurity in infants $\geq 1500 \mathrm{~g}$ birth weight. Indian J Ophthalmol. 2014; 62:254-257. https://doi.org/10.4103/0301-4738.128639

24. Kychenthal A, Dorta P and Katz X. Zone I retinopathy of prematurity: clinical characteristics and treatment outcomes. Retina. 2006; 26(7 Suppl): S11-S15. https://doi.org/10.1097/01.iae.0000244285.79004.e6

25. Vander JF, Handa J, McNaara JA, Li H, Morse LS and Tasman WS. Early treatment of posterior retinopathy of prematurity, a controlled trial. Ophthalmology. 1997; 104:1731-1736. https://doi.org/10.1016/S0161-6420(97)30034-7

26. Fleming $\mathrm{TH}$, Runge $\mathrm{PE}$ and Charles ST. Diode laser photocoagulation for prethreshold posterior retinopathy of prematurity. Am J Ophthalmol. 1992;114:589-592. https://doi.org/10.1016/S0002-9394(14)74488-5

27. Shapiro MJ, Gieser JP, Warren KA, Resnick KI and Blair NP. Zone 1 retinopathy of prematurity. In: Shapiro MJ, editor. Retinopathy of Prematurity: proceedings of the international conference on retinopathy of prematurity. New York: Kugler Publications; 1995. p. 49-155.

\footnotetext{
Author's contribution:

PG- Interpreted the results and statistically analysed, reviewed the literature, prepared first draft of manuscript; PK- Concept and design the study, interpreted the results, reviewed the literature, revision of manuscript, coordination; KS- Concept and design the study, interpreted the results, reviewed the literature, revision of manuscript; BS- Manuscript preparation, reviewed the literature, statistically analyzed and interpreted results.

Work attributed to:

Government Medical College, Amritsar, Punjab, India.

Orcid ID:

Dr. Parveen Grang- (iD https://orcid.org/0000-0002-6496-0911

Dr. Prempal Kaur- (1) https://orcid.org/0000-0002-4587-9042

Dr. Karamjit Singh- (1) https://orcid.org/0000-0001-9665-4188

Dr. Bhavkaran Singh- (1) https://orcid.org/0000-0003-1003-4899

Source of Funding: None, Conflict of Interest: None.
} 